\title{
Multicenter study of the long-term outcomes of endoscopic submucosal dissection for early gastric cancer in patients 80 years of age or older
}

\author{
Nobutsugu Abe $\cdot$ Takuji Gotoda $\cdot$ Toshiaki Hirasawa $\cdot$ Shu Hoteya $\cdot$ Kenji Ishido $\cdot$ \\ Yosuke Ida · Hiroyuki Imaeda · Eiji Ishii · Atsushi Kokawa · Chika Kusano · Tadateru Maehata • \\ Satoshi Ono $\cdot$ Hirohisa Takeuchi $\cdot$ Masanori Sugiyama $\cdot$ Shinichi Takahashi
}

Received: 15 April 2011/Accepted: 17 May 2011/Published online: 11 June 2011

(C) The International Gastric Cancer Association and The Japanese Gastric Cancer Association 2011

\begin{abstract}
Background Little information is available on the longterm outcomes of endoscopic submucosal dissection (ESD) for early gastric cancer (EGC) in patients of advanced age ( $\geq 80$ years).

Methods A multicenter study was conducted at 10 Japanese institutions concerning their results for ESD. Data on 440 patients of advanced age ( $\geq 80$ years) with EGC (470 lesions) were collected and reviewed. Early and long-term outcomes of ESD were assessed. We compared the overall survival rates between 3 patient groups, those with curative
\end{abstract}

\footnotetext{
N. Abe $(\bowtie) \cdot H$. Takeuchi $\cdot$ M. Sugiyama

Department of Surgery, Kyorin University School of Medicine,

6-20-2 Shinkawa, Mitaka, Tokyo 181-8611, Japan

e-mail: abenbtg@ks.kyorin-u.ac.jp

T. Gotoda $\cdot$ C. Kusano

Department of Gastroenterology and Hepatology,

National Center for Global Health and Medicine, Tokyo, Japan

T. Hirasawa

Endoscopy Division, Cancer Institute Hospital, Tokyo, Japan

S. Hoteya

Department of Gastroenterology, Toranomon Hospital,

Tokyo, Japan

K. Ishido

Department of Gastroenterology, Kitasato University East

Hospital, Kanagawa, Japan

Y. Ida $\cdot$ H. Imaeda

Division of Gastroenterology, Department of Internal Medicine,

School of Medicine, Keio University, Tokyo, Japan

H. Imaeda

Department of General Internal Medicine,

Saitama Medical University, Saitama, Japan
}

ESD, additional surgery after noncurative ESD, and nonsurgical follow-up after noncurative ESD.

Results Bleeding and perforation rates were 3.2 and $2.8 \%$, respectively. Curative ESD was achieved in 366 of the 470 lesions $(77.9 \%)$. Of the 104 patients with noncurative ESD, 12 patients (11.5\%) underwent additional surgery and 91 patients (87.5\%) were followed without surgery. The 5-year survival rate in the patients with nonsurgical follow-up after noncurative ESD (66.7\%) was significantly lower than that in the patients with curative ESD $(80.3 \%, p=0.0001)$. There was no significant

E. Ishii

Department of Gastroenterology, Kameda Medical Center,

Chiba, Japan

\author{
A. Kokawa \\ Department of Gastroenterology, Yokohama City University \\ Medical Center, Kanagawa, Japan \\ C. Kusano \\ Department of Endoscopy, National Cancer Center Hospital, \\ Tokyo, Japan \\ T. Maehata \\ Department of Gastroenterology and Hepatology, \\ Internal Medicine, St Marianna University School of Medicine, \\ Kanagawa, Japan \\ S. Ono \\ Department of Gastroenterology, Graduate School of Medicine, \\ The University of Tokyo, Tokyo, Japan \\ S. Takahashi \\ The Third Department of Internal Medicine, \\ Kyorin University School of Medicine, Tokyo, Japan
}


difference in the 5-year survival rates between the patients with curative ESD and those with surgery after noncurative $\operatorname{ESD}(100 \%, p=0.21)$, nor was there a difference in these rates between the patients with surgery after noncurative ESD and those with nonsurgical follow-up after noncurative $\operatorname{ESD}(p=0.061)$. None of the patients developed cancer recurrence after curative ESD, and none developed cancer recurrence following the additional surgery after noncurative ESD. In the patients with curative ESD and in those with surgery after noncurative ESD, the cumulative observed survival was better than the expected survival for the general population of similar age and gender.

Conclusions ESD is safe for the treatment of EGC in patients 80 years of age or older. Both curative ESD and additional surgery after noncurative ESD may contribute to the extension of life expectancy.

Keywords Early gastric cancer - Endoscopic submucosal dissection (ESD) · Elderly · Multicenter study

\section{Introduction}

Early gastric cancer (EGC), which is associated with a 5-year-survival rate of $90 \%$, is diagnosed in more than $50 \%$ of patients with gastric cancer in Japan [1]. As the general population ages, larger numbers of elderly patients with EGC will be candidates for endoscopic resection.

Endoscopic submucosal dissection (ESD) is widely recognized as a safe and effective treatment of EGC [2-5], even in aged or high-risk patients [6-10]. However, little information is available on the long-term outcomes of ESD in a large number of elderly patients. To evaluate these outcomes, a retrospective multicenter study was conducted at 10 Japanese institutions concerning their results for ESD in patients of advanced age ( $\geq 80$ years).

\section{Patients and methods}

Patients and indications for ESD

Ten Japanese institutions participating in this study were selected from major centers with accumulated experience in ESD for EGC (Table 1). This study was carried out with the approval of the institutional review board of each institution.

EGC is defined as a lesion confined to the mucosa or submucosa regardless of the presence or absence of lymph node metastasis, according to the Japanese classification of gastric carcinoma established by the Japanese Gastric Cancer Association [11]. We collected data of 440 patients who had undergone ESD for EGC (470 lesions) between August 2001 and July 2009 and who were able to be followed for more than 2 years after the ESD (also included are the data of the patients who died for some reason within 2 years after the ESD) (Table 1). Data on clinicopathological characteristics and early and long-term outcomes were collected and analyzed in July 2010, according to the ethical guidelines for epidemiological research proposed by the Ministry of Education, Culture, Sports, Science and Technology of Japan and the Ministry of Health, Labour and Welfare of Japan.

The indications for ESD were basically determined on the basis of the presence or absence of nodal metastasis [12-14] and on the basis of the criteria for endoscopic resection proposed in the Treatment guidelines for gastric cancer in Japan [15]. The indication criteria are listed in

Table 1 Participating institutions and numbers of patients (lesions)

\begin{tabular}{lr}
\hline Institutions & $\begin{array}{l}\text { Number of } \\
\text { patients (lesions) }\end{array}$ \\
\hline 1. Department of Gastroenterology, Toranomon Hospital, Tokyo & $17(17)$ \\
2. Department of Gastroenterology, Kitasato University East Hospital, Kanagawa & $42(45)$ \\
3. Department of Internal Medicine, School of Medicine, Keio University, Tokyo & $17(17)$ \\
4. Department of Gastroenterology, Graduate School of Medicine, The University of Tokyo, Tokyo & $22(22)$ \\
5. Department of Gastroenterology, Yokohama City University Medical Center, Kanagawa & 73 (75) \\
6. Endoscopy Division, Cancer Institute Hospital, Tokyo & $30(30)$ \\
7. Department of Gastroenterology and Hepatology, St Marianna University School of Medicine, Kanagawa & $58(58)$ \\
8. Department of Endoscopy, National Cancer Center Hospital, Tokyo & $124(142)$ \\
9. Department of Surgery, Kyorin University School of Medicine, Tokyo & $27(31)$ \\
10. Department of Gastroenterology, Kameda Medical Center, Chiba & 30 (33) \\
Total & $440(470)$ \\
\hline
\end{tabular}


Table 2 Indication criteria for endoscopic submucosal dissection (ESD)

1. Differentiated-type mucosal cancer without ulceration

2. Differentiated-type mucosal cancer with ulceration and up to $3 \mathrm{~cm}$ in diameter

3. Undifferentiated-type mucosal cancer without ulceration and up to $2 \mathrm{~cm}$ in diameter

4. Differentiated-type minute submucosal cancer (SM1) without ulceration and smaller than $3 \mathrm{~cm}$ in diameter

Table 2. This study also included patients who had not met these criteria (for various reasons) and who had undergone ESD.

\section{Clinicopathological characteristics}

The location of the tumor was classified as upper, middle, and lower stomach according to the Japanese classification of gastric carcinoma established by the Japanese Gastric Cancer Association [11]. Macroscopic type was divided into elevated type and depressed and/or flat type.

\section{Early outcomes}

The early outcomes (bleeding and perforation rates, procedure-related mortality, and curability) were assessed. Bleeding was defined based on clinical evidence of bleeding with occurrence of melena and/or hematemesis, or by confirmation of blood or coagulated blood in the stomach and bleeding spots by endoscopy. Perforation was confirmed endoscopically during the procedure and/or by the presence of free air on plain abdominal radiographs after the ESD. Procedure-related mortality was defined as death due to complications such as perforation or bleeding within 30 days after the ESD.

Curability was assessed histologically, on the basis of the indication criteria for ESD, tumor margin status, and the presence or absence of lymphovascular invasion, as curative and noncurative. When a tumor was within the indication criteria with tumor-free margins and absence of lymphovascular invasion, the curability was defined as curative. When histological evaluation was difficult, or revealed that a lesion was outside the indication criteria and/or that it had a positive margin or lymphovascular invasion, the curability was defined as noncurative.

\section{Long-term outcomes}

Patient survival was estimated in three patient groups, those with curative ESD, additional surgery after noncurative ESD, and nonsurgical follow-up after noncurative ESD. We compared the overall survival rates between
Table 3 Patient and tumor characteristics

\begin{tabular}{ll}
\hline Parameters & $\begin{array}{l}\text { No. of patients }(n=440) \\
\text { or tumors }(n=470)\end{array}$ \\
\hline $\begin{array}{l}\text { Age, years, mean (range) } \\
\text { Sex ratio (M/F) }\end{array}$ & $82(80-93)$ \\
Tumor location & $314 / 126$ \\
Upper third & $101(21.5 \%)$ \\
Middle third & $153(32.6 \%)$ \\
Lower third & $216(45.9 \%)$ \\
Macroscopic type & \\
Elevated & $232(49.4 \%)$ \\
Depressed and/or flat & $238(50.6 \%)$ \\
\hline
\end{tabular}

Table 4 Early outcomes of ESD

\begin{tabular}{lc}
\hline & $\begin{array}{l}\text { No. of patients }(n=440) \\
\text { or tumors }(n=470)\end{array}$ \\
\hline Bleeding & $15(3.2 \%)$ \\
Perforation & $13(2.8 \%)$ \\
Procedure-related death & $0(0 \%)$ \\
Curability & \\
$\quad$ Curative resection & $366(77.9 \%)$ \\
$\quad$ Noncurative resection & $104(22.1 \%)$ \\
\hline
\end{tabular}

a When a tumor was within the indication criteria, with tumor-free margins, the curability was defined as curative. When histological evaluation was difficult, or, revealed that a lesion was outside the indication criteria and/or that it had a positive margin, the curability was defined as noncurative

these 3 patient groups. Expected patient survival was computed for persons of similar age, gender, and calendar year of birth based on cohort life tables constructed for Japan [16].

Statistical analysis

Patient survival was estimated using the Kaplan-Meier method. Differences were considered significant when $p<0.05$.

\section{Results}

Early outcomes

The patients' clinicopathological characteristics are shown in Table 3. The patients were 314 men and 126 women with a mean age of 82 years (range 80-93 years).

Bleeding and perforation rates were 3.2 and $2.8 \%$, respectively (Table 4). Although no deaths related to ESD occurred, one patient died of a cardiac event during the 
Fig. 1 Clinical outcomes of endoscopic submucosal dissection (ESD)

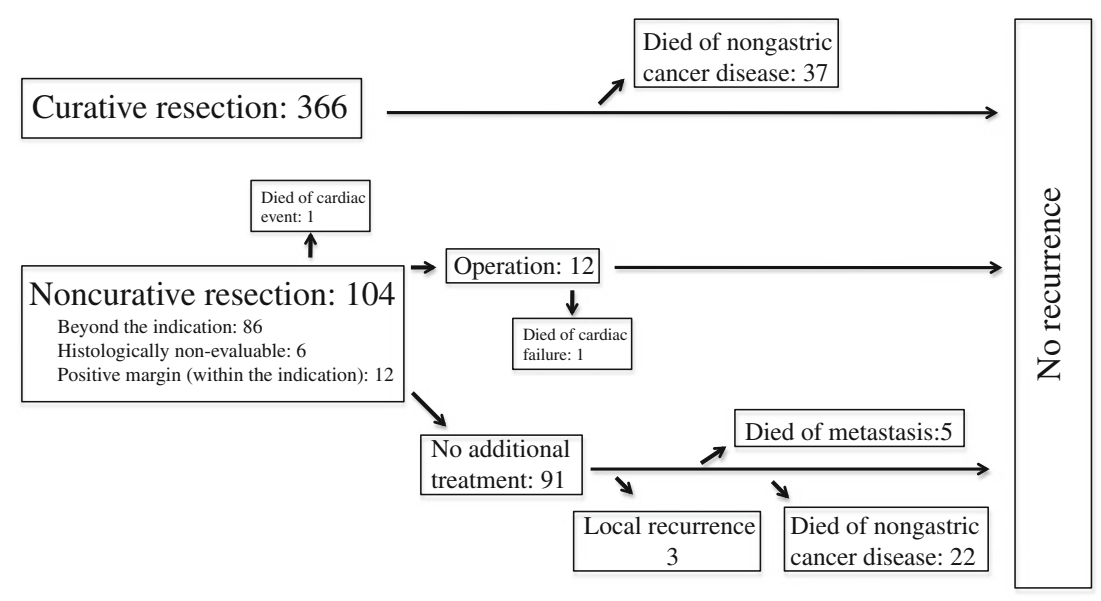

hospital stay (on post-ESD day 10). The complication rate (bleeding and perforation) was similar to those in other reports [2-10], showing that ESD was mostly safely performed even in the elderly. Curative ESD was achieved in 366 of 470 lesions (77.9\%). Of the 104 patients with noncurative ESD, 12 patients $(11.5 \%)$ underwent additional surgery, and the remaining 91 patients $(87.5 \%)$ were followed without surgery (Fig. 1). One patient died of cardiac failure after the additional surgery during the hospital stay.

\section{Long-term outcomes}

The overall median follow-up period was 41 months (range 2-99). Of the 366 patients with curative ESD, 37 patients $(10.1 \%)$ died of nongastric cancer disease, and none of the remaining 329 patients $(89.8 \%)$ developed cancer recurrences (Fig. 1). Of the 104 patients with noncurative ESD, none of the 11 patients who underwent additional surgery developed cancer recurrences. Of the 91 patients with nonsurgical follow-up after noncurative ESD, three patients (3.3\%) developed local recurrence, and five (5.5\%) and $22(24.2 \%)$ patients died of gastric cancer metastasis and nongastric cancer disease, respectively. None of the remaining 61 patients $(67 \%)$ developed cancer recurrences.

The median follow-up period in the patients with curative ESD, surgery after noncurative ESD, and nonsurgical follow-up after noncurative ESD was 38.5, 44, and 33 months, respectively. The overall 5-year survival rates in these three groups were $80.3 \%, 100 \%$ (excluding one patient who died of cardiac failure after the surgery), and $66.7 \%$, respectively (Fig. 2). The 5-year survival rate in the patients with nonsurgical follow-up after noncurative ESD was significantly lower than that in the patients with curative $\operatorname{ESD}(p=0.0001)$. There was no significant difference in the 5-year survival rates between the patients

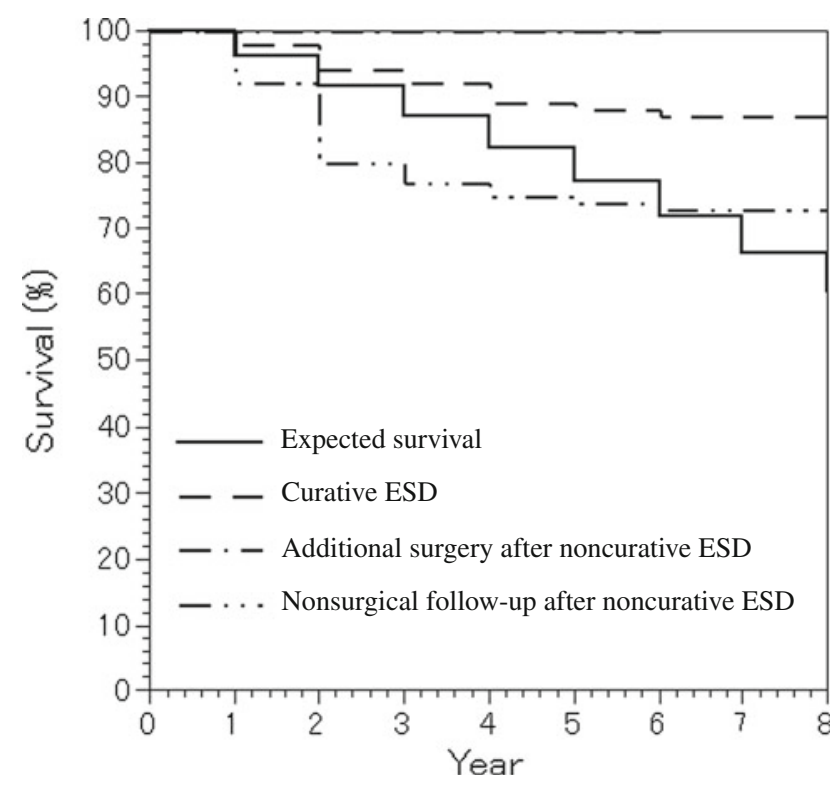

Fig. 2 Observed patient survival in each group, and expected survival. The expected survival was based on that of persons of similar age, gender, and calendar year of birth, using life tables for death from all causes for Japan [15]

with curative ESD and those with surgery after noncurative $\operatorname{ESD}(p=0.21)$, nor was there a significant difference in the 5 -year survival rates between the patients with surgery after noncurative ESD and those with nonsurgical follow-up after noncurative $\operatorname{ESD}(p=0.061)$. In the patients with curative ESD and those with surgery after noncurative ESD, the cumulative observed survivals of $80.3,100$, and $65 \%$ at 5 years after ESD were better than the expected survival for the general population of similar age and gender. In the patients with nonsurgical follow-up after noncurative ESD, the cumulative observed survival of 66.7 and $65 \%$ at 5 years after ESD was comparable to the expected value for the general population of similar age and gender. 


\section{Discussion}

According to the fiscal 2008 statistics published by the Ministry of Health, Labour and Welfare, the mean life spans in Japan for men and women, respectively, were 79 and 86 years, and the mean life expectancies at the age of 80 years were 8 and 11 years for men and women, respectively [16]. With the coming of such a superaging era, endoscopic treatment has been increasingly performed for EGC in the elderly, and it has been established as a safe and minimally invasive technique [6-10]. However, only one report has been published on the long-term outcomes of endoscopic treatment for EGC in a large number of patients of advanced age [17]. Moreover, the natural history of EGC has been poorly clarified. Therefore, whether EGC affects the prognosis of patients of advanced age, regardless of the presence or absence of a therapeutic intervention, has not been fully clarified. With these features as a background, the present retrospective multicenter study was carried out to determine the early and long-term outcomes of ESD in the elderly (age 80 years or older) and to clarify the validity of ESD.

In the examination of long-term outcomes, the patients with curative ESD did not show cancer recurrence, and were only followed up after ESD. Although $12.8 \%$ of the patients in this group died of nongastric cancer disease, the overall survival rate of this group was better than the expected survival rate of the general population. This finding suggests that the active implementation of ESD will contribute to the extension of life expectancy even in patients of advanced age with EGC when a lesion fulfills the indication criteria for endoscopic treatment, as Kusano et al. [17] have recently demonstrated. However, in the present study, the elderly patients who received endoscopic examination, therapy, and/or additional surgery could have been healthier and could have had a better performance status than the general elderly population. Thus, we should pay special attention to this potential selection bias in the present study.

In clinical practice, when an ESD specimen is diagnosed as being beyond the indication criteria for endoscopic treatment on the basis of histopathological analysis, we often face the problem of deciding whether additional surgery should be performed; this choice is faced in younger patients as well as in patients of advanced age. In patients of advanced age, however, the appropriate surgical treatment should be selected considering background factors such as the presence or absence of dementia or chronic comorbidities, and the use of anticoagulation agents, as well as considering the decrease in the patient's quality of life after the surgery. In addition, the fact that death from nongastric cancer disease reduces the survival rate in patients of advanced age compared with that in younger patients should be considered.
In the present study, $87.5 \%$ of the 104 patients with noncurative ESD did not undergo additional surgery but were only followed up. Of these, $24.2 \%$ died of nongastric cancer disease, and inevitably, a considerable number of patients $(5.5 \%)$ died of cancer metastasis. Background factors such as the presence or absence of dementia or chronic comorbidities, and the use of anticoagulation agents, were not considered in this study. Therefore, there might have been a bias because the group with nonsurgical follow-up after noncurative ESD would have included many patients with difficulties in undergoing surgery or those who were assessed as having a higher risk of death from nongastric cancer disease even before the ESD. It is presumed that many such patients were followed up because of factors unique to the elderly that cannot be quantified in numerical terms. However, the patients who underwent additional surgery after noncurative ESD did not develop recurrence. Moreover, nongastric cancer death was not found in such patients. Therefore, it may be desirable to perform additional surgery when possible after noncurative ESD, although in the present study there might also have been a bias because the patients in the group with additional surgery after noncurative ESD did not have a risk of death from nongastric cancer disease. In fact, Kusano et al. [17] have recently shown that additional surgery following noncurative endoscopic resection improved survival in elderly patients. On the other hand, in the present study, because the overall survival rate $(66.7 \%)$ in the patients with nonsurgical follow-up after noncurative ESD was similar to the expected survival rate $(65 \%)$ of the general population, it is possible that local control provided by ESD alone may be significant even in such patients. A prospective study of the followed-up patients is necessary to establish the significance of ESD in these patients. However, such a clinical investigation has major ethical issues because the lesions that do not meet the indication criteria for endoscopic treatment have a possibility of lymph node metastasis and are therefore beyond the indication for endoscopic resection in the first place. In the meantime, it is necessary to select the appropriate treatment for the individual patient in clinical practice, to accumulate cases of patients whose lesions are outside the criteria for endoscopic treatment who are only followed up after ESD, and to conduct a retrospective multiple-case study of the cases thus accumulated.

In conclusion, ESD is safe for the treatment of EGC in patients 80 years of age or older. Both curative ESD and additional surgery after noncurative ESD may contribute to the extension of life expectancy. However, careful followup after noncurative ESD (namely, ESD only) can be one of the options in patients of advanced age who have difficulties in undergoing surgery or who are assessed as having a high risk of death from nongastric cancer disease. 
Acknowledgments The authors thank Dr. Yutaka Suzuki for his statistical analysis.

\section{References}

1. Kitano S, Shiraishi N. Current status of laparoscopic gastrectomy for cancer in Japan. Surg Endosc. 2004;18:182-5.

2. Ono H, Kondo H, Gotoda T, Shirao K, Yamaguchi H, Saito D, et al. Endoscopic mucosal resection for treatment of early gastric cancer. Gut. 2001;48:225-9.

3. Abe N, Yamaguchi Y, Takeuchi H, Izumisato Y, Yanagida O, Masaki T, et al. Key factors for successful en bloc endoscopic submucosal dissection of early stage gastric cancer using an insulation-tipped diathermic knife. Hepatogastroenterology. 2006;53:639-42.

4. Oda I, Saito D, Tada M, Iishi H, Tanabe S, Oyama T, et al. A multicenter retrospective study of endoscopic resection for early gastric cancer. Gastric Cancer. 2006;9:162-70.

5. Gotoda T. Endoscopic resection of early gastric cancer. Gastric Cancer. 2007;10:1-11

6. Hirasaki S, Tanimizu M, Nasu J, Shinji T, Koide N. Treatment of elderly patients with early gastric cancer by endoscopic submucosal dissection using an insulated-tip diathermic knife. Intern Med. 2005;44:1033-8.

7. Kakushima N, Fujishiro M, Kodashima S, Muraki Y, Tateishi A, Yahagi N, et al. Technical feasibility of endoscopic submucosal dissection for gastric neoplasms in the elderly Japanese population. J Gastroenterol Hepatol. 2007;22:311-4.

8. Isomoto H, Ohnita K, Yamaguchi N, Fukuda E, Ikeda K, Nishiyama $\mathrm{H}$, et al. Clinical outcomes of endoscopic submucosal dissection in elderly patients with early gastric cancer. Eur J Gastroenterol Hepatol. 2010;22:311-7.
9. Kim BJ, Chang TH, Kim JJ, Min BH, Lee JH, Son HJ, et al. Efficacy and safety of endoscopic submucosal dissection for early gastric cancer in patients with comorbid diseases. Gut Liver. 2010;4:186-91.

10. Toyokawa T, Fujita I, Morikawa T, Okamoto A, Miyasaka R, Watanabe $\mathrm{K}$, et al. Clinical outcomes of ESD for early gastric neoplasms in elderly patients. Eur J Clin Invest. 2011;41:274-8.

11. Japanese Gastric Cancer Association. Japanese classification of gastric carcinoma. 2nd English edition. Gastric Cancer. 1998;1:10-24.

12. Gotoda K, Yanagisawa A, Sasako M, Ono H, Nakanishi Y, Simoda $\mathrm{T}$, et al. Incidence of lymph node metastasis from early gastric cancer. The estimation using a large number of cases in two large centers. Gastric Cancer. 2000;3:219-25.

13. Gotoda T, Iwasaki M, Kusano C, Seewald S, Oda I. Endoscopic resection of early gastric cancer treated by guideline and expanded National Cancer Centre criteria. Br J Surg. 2010;97:868-71.

14. Hirasawa T, Fujisaki J, Fukunaga T, Yamamoto Y, Yamaguchi T, Katori $\mathrm{M}$, et al. Lymph node metastasis from undifferentiatedtype mucosal gastric cancer satisfying the expanded criteria for endoscopic resection based on routine histological examination. Gastric Cancer. 2009;12:148-52.

15. Japanese Gastric Cancer Association. Treatment Guidelines for Gastric Cancer in Japan (in Japanese). 3rd ed. Tokyo: Kanehara; 2010.

16. Statistics and Information Department, Minister's Secretariat, Ministry of Health and Welfare of Japan. The abridged life table. Tokyo; 2008.

17. Kusano C, Iwasaki M, Kaltenbach T, Conlin A, Oda I, Gotoda T. Should elderly patients undergo additional surgery after noncurative endoscopic resection for early gastric cancer-long term comparative outcomes. Am J Gastroenterol. 2011 Mar 15 [Epub ahead of print]. 